\title{
Tackling mental health: the role of professional football clubs.
}

\author{
Kathryn Curran ${ }^{\mathrm{a}}$, Simon Rosenbaum ${ }^{\mathrm{b}}$, Daniel Parnell ${ }^{\mathrm{c}}$, Brendon Stubbs $^{\mathrm{d}, \mathrm{e}}$,
} Andy Pringle and Jackie Hargreaves ${ }^{\mathrm{a}}$.

${ }^{a}$ Centre for Active Lifestyles, Carnegie Faculty, Leeds Beckett University, Leeds, LS6 3QS, UK.

${ }^{\mathrm{b}}$ Department of Exercise Physiology, Faculty of Medicine, University of New South Wales, Sydney, NSW, Australia

${ }^{\mathrm{c}}$ Business in Sport Knowledge Cluster, Centre for Business and Society, Faculty of Business and Law, Business School, Manchester Metropolitan University, M15 6BH, UK.

d Physiotherapy Department, South London and Maudsley NHS Foundation Trust, Denmark Hill, London SE5 8AZ, United Kingdom

${ }^{e}$ Health Service and Population Research Department, Institute of Psychiatry, Psychology and Neuroscience, King's College London, De Crespigny Park, London Box SE5 8 AF, United Kingdom

Corresponding author. Email: k.m.curran@ leedsbeckett.ac.uk

Author emails:

SR s.rosenbaum@unsw.edu.au;

DP $\underline{\text { d.parnell@mmu.ac.uk; }}$

BS brendon.stubbs@kcl.ac.uk;

AP A.Pringle@leedsbeckett.ac.uk;

JH J.Hargreaves@leedsbeckett.ac.uk 


\title{
Tackling mental health: the role of professional football clubs.
}

\author{
Kathryn Curran ${ }^{\mathrm{a}}$, Simon Rosenbaum ${ }^{\mathrm{b}}$, Daniel Parnell ${ }^{\mathrm{c}}$, Brendon Stubbs ${ }^{\mathrm{d}, \mathrm{e}}$, \\ Andy Pringle and Jackie Hargreaves ${ }^{\mathrm{a}}$.
}

In the UK professional football clubs are being used as settings for the delivery of interventions that promote mental health in a number of ways including (i) the delivery of physical activity interventions to improve the mental health of the general population, (ii) the delivery of physical activity interventions for people experiencing mental illness, and (iii) the delivery of community mental health services within the confines of the football club. This research note offers insights into mental health interventions delivered within, and by, professional football clubs and the available evidence concerning their reach, effectiveness and impact. The findings suggest that professional football clubs can help to facilitate access to mental health services, particularly among young people, for whom accessing such services may be highly stigmatised. Furthermore, the findings highlight that such interventions have a positive impact on health. However, in order to capitalise on this opportunity funding agencies and commissioners must provide appropriate resources (human and financial) for effective delivery and evaluation. Furthermore, a more strategic approach to working towards the mental health agenda must be adopted. It is argued that this change in practice would allow professional football clubs to offer those in need access to high quality interventions.

Key words: Mental Health, Mental Illness, Football, Public Health, Intervention.

\section{Background}

Mental health is more than simply the lack of mental illness. Rather, it is a positive concept related to the social and emotional well-being of both individuals and communities and relating to the enjoyment of life, ability to cope with stress and sadness, the fulfilment of goals and potential, and a sense of connection to others (Hunter Institute 
of Mental Health 2015). A mental illness is a disorder diagnosed by a medical professional that significantly interferes with an individual's cognitive, emotional or social abilities. Mental illnesses can include mood disorders (such as depression, anxiety, and bipolar disorder), psychotic disorders (such as schizophrenia), eating disorders and personality disorders (Hunter Institute of Mental Health 2015).

Mental illness is a considerable burden on public health; depression alone accounts for one of the top five most commonly managed conditions in general practice (Cooke et al. 2012). In addition to negatively impacting upon quality of life, well-being and psychosocial functioning, there is irrefutable evidence demonstrating a strong association between mental illness and poor physical health such as obesity, diabetes and cardiovascular disease (Vancampfort, Stubbs, Mitchell, et al. 2015). Collectively, the great increase in co-morbid somatic conditions contribute to a 15-20 year gap in life expectancy compared to the general population (Lawrence, Hancock, and Kisely 2013, Laursen, Munk-Olsen, and Vestergaard 2012), a finding that has been coined a scandal of premature mortality (Thornicroft 2011).

Factors contributing to the increased burden of poor physical health among people experiencing mental illness include psychotropic medication (Perez-Iglesias et al. 2008, Alvarez-Jimenez et al. 2008) and lifestyle related modifiable risk factors, such as physical inactivity (Nyboe and Lund 2013, Vancampfort, Knapen, et al. 2012), poor dietary intake (Dipasquale et al. 2013), and high rates of smoking (Britton 2015). While physical activity remains the cornerstone of cardiovascular disease treatment in the general population (Thompson et al. 2003), people experiencing mental illness engage in less physical activity and frequently do not meet physical activity recommendations (Snethen, McCormick, and Lysaker 2014, Gardner-Sood et al. 2015, Vancampfort, Probst, Knapen, et al. 2012, Nyboe and Lund 2013).

In addition to the range of physical health benefits of regular physical activity participation, a growing body of evidence has demonstrated that physical activity has both protective (Mammen and Faulkner 2013) and treatment effects for people with mental illnesses (Rosenbaum et al. 2014). Importantly, even modest increases in physical activity are associated with improved mental health outcomes (Vancampfort, Stubbs, Ward, et al. 2015a), with available recommendations regarding intervention variables 
comparable to those applicable to the general population (Stanton et al. 2014, Stanton and Reaburn 2014, Vancampfort, De Hert, et al. 2012). Considerable evidence has demonstrated both an anti-depressive (Schuch et al. 2016) and anxiolytic (Jayakody, Gunadasa, and Hosker 2013) effect of physical activity, in addition to improving symptoms of other conditions, such as schizophrenia (Firth et al. 2015, Vancampfort, Probst, Skjaerven, et al. 2012). Furthermore, physical activity has been found to be beneficial for promoting quality of life and recovery in people experiencing mental illness (Holley et al. 2011, Carless and Douglas 2008).

Despite recent and ongoing calls for physical activity to be an integral component of psychiatric care (Vancampfort, Stubbs, Ward, et al. 2015b, Vancampfort, Stubbs, Ward, et al. 2015a, Rosenbaum et al. 2015, Vancampfort and Faulkner 2014, Stanton et al. 2015) universal access to physical activity programmes for people experiencing mental illness remains ad-hoc in many jurisdictions, often with limited funding and resources available to support clinical exercise programmes (Medicine 2015).

The efficacy of physical activity for improving mental health of the general population and people experiencing mental illness has been established (Rosenbaum et al. 2014, Rebar et al. 2015). However, there is an urgent need to ensure that these findings are translated into real world programmes capable of engaging and motivating people experiencing mental illness to participate in regular physical activity (Vancampfort, Stubbs, Ward, et al. 2015b, Vancampfort, Stubbs, Ward, et al. 2015a). One potential and highly scalable approach to promoting physical activity among people with mental illness is the utilisation of professional football clubs to deliver pragmatic, community-based interventions (Pringle, 2009, Parnell and Curran 2015).

In the UK, professional football clubs have received an increasing amount of attention with regards to their potential ability to contribute to the public health agenda. Over the past three years there have been a rolling number of research articles discussing the role of professional football clubs in health improvement. The publication of a special issue on 'Football and Inclusivity' in the peer reviewed journal 'Soccer and Society' (Parnell and Richardson 2014), for example, housed a number of key articles which highlighted professional football clubs as a vehicle for health promotion (Curran et al. 
2014, Bingham et al. 2014, Curran, Drust, and Richardson 2014, Rutherford et al. 2014, Pringle, Parnell, et al. 2014).

Further developments in the football and health movement have been led by colleagues in Scotland (Hunt et al. 2014), who recorded significant biopsychosocial outcomes emerging from a randomized control trial related to a physical activity-led weight management programme for men, delivered through professional football clubs. Moreover, articles related to football and health related programmes for men and older adults have also emerged (Pringle, Parnell, et al. 2014). Most recently, Parnell and Pringle (2016) released a special issue on football and health improvement, which housed an eclectic mix of research articles and commentaries related to the role of professional football clubs in health improvement (Lansley and Parnell 2015, Pringle et al. 2015, Hulton et al. 2015).

Professional football clubs' Football in the Community (FitC) programmes often use football as an activity to engage participants in mental health interventions (Henderson et al. 2014). Research provides evidence of how football can support the prevention, early intervention, treatment and rehabilitation of a range of diseases across the lifespan (Krustrup et al. 2010, Bangsbo et al. 2014). The current understanding shows that football can be a valuable and acceptable health improvement activity, that has the potential to reach those at-risk of, and those diagnosed with, mental illness and improve mental health and well-being (Ottesen, Jeppesen, and Krustrup 2010, Krustrup et al. 2013, Elbe et al. 2015 [In press]).

Professional football clubs' community physical activity and health programmes have demonstrated huge success in both engaging and retaining their target audiences (Curran et al. 2014, Pringle et al. 2014, Pringle et al. 2015). Promoting and engaging the public in public health messages during leisure time has also been successfully achieved through associations with professional football clubs (Pringle et al. 2011, Curran et al. 2014). For example, awareness and engagement in positive health behaviours and messages has been achieved with men on English Premier League match days through a variety of approaches (Curran et al. 2014). These approaches were based on the assumption that the men would respond to health messages, seek help and discuss taboo issues in places that they feel comfortable (Pringle et al., 2011, Robertson et al. 2013). 
The culture of football clubs therefore, can create an environment with the potential to address and ameliorate poor mental health amongst the community.

Research reflects an increasing interest and evidence for professional football clubs as a vehicle for health promotion. At present, in the UK, there are an increasing number of applied interventions targeting mental health promotion, or specifically tackling mental illness. Offering such interventions is a valuable, normalising and nonstigmatising approach to increasing physical activity. Professional football clubs have been used as settings for the delivery of interventions that promote mental health in a number of ways including (i) the delivery of physical activity interventions to improve the mental health of the general population, (ii) the delivery of physical activity interventions for people experiencing mental illness, and (iii) the delivery of community mental health services within the confines of the football club. Despite this growing investment there is very little evidence surrounding the impact of such interventions.

\section{Programmes and Evidence}

\section{The delivery of physical activity interventions to improve the mental health of the general population}

The delivery of lifestyle interventions which include a physical activity component have included the assessment of mental and social well-being. Premier League Health (PLH) for example, was a three year national programme of men's health delivered in, and by, professional football clubs in England. Through their evaluation of PLH, White and colleagues (2012) highlighted that $15 \%$ of participants showed a positive change in social support, with $7 \%$ of participants moving to a level where they felt that they had forged social support networks that they could rely on in times of trouble (White et al. 2012). While some men self-reported reductions in social support pre-versus-post intervention, overall there was a statistically significant improvement in the social support networks of completers engaging in PLH. Further, interviews $(n=57)$ with participants supported that those individuals completing interventions reported positive psychological well-being, including achievement, feelings of well-being and social support (Pringle, Zwolinsky, et al. 2014). 
Older adults represent a core priority group for physical activity, mental health and public health policy (DH, 2015). Professional football clubs have featured in many approaches to tackle public health priorities in this group (Bingham et al. 2014, Pringle, Zwolinsky, et al. 2014). An example is Extra Time (ET), a national programme of physical activity interventions, delivered in professional football clubs, for older adults aged 55+ years. ET engaged older adults in weekly classes of a broad menu of physical and social activities, delivered primarily within football stadia. Participants reported that the link with the professional football club made ET more appealing. The most frequently self-reported benefits of engaging with ET were making friends, having fun and feeling happier with life (Parnell et al. 2015).

\section{The delivery of physical activity interventions for people experiencing mental illness}

The 'Imagine Your Goals' (IYG) programme (Henderson et al. 2014) in an ongoing mental health intervention which aims to improve social inclusion and well-being for people with mental illnesses, as well as tackle mental health stigma and discrimination. The programme was pioneered by Everton in the Community (Everton Football Club's FitC programme) and adopted and rolled out by the Premier League in 2011. IYG is now delivered by 16 English Premier League football clubs, in conjunction with England's Time to Change programme (Barclays Premier League 2016). A mixed methods evaluation captured pre-versus-post- intervention data on participants' well-being, and access to social capita (Henderson et al. 2014). Results indicated significant improvements in personal and individual skills, post-intervention. Focus groups were conducted with participants at the outset and the end of the two-year programmes. Participants reported that the programme had met their expectations in a number of areas including socialising, health and fitness. The authors of the report (Henderson et al 2014) concluded football clubs can successfully deliver programmes to people with mental illness which improve access to personal skills, social capital and have other potential benefits.

Notts County Football in the Community (NCFC) located in the English East Midlands, established a weekly group providing sport and physical activities for men with early onset dementia. Participants engaged in a wide range of gentle and easy-to- 
follow weekly activities including walking football, bowls, cricket, basketball, table tennis, volleyball and badminton. Participants and their carers were consulted about what activities they would like to take part in prior to the session (Notts Country Football in the Community 2013). In contrast, the social part of the session gave participants the chance to engage in conversation, create social connections and relax in the company of

others while having refreshments. Investigating this intervention, Carone, Tischler and Dening (2014) reported enjoyment and positive anticipation related to attending the group for all involved. The 'brand' of the football club (named the 'The Notts County Effect') and the personalised service in a 'dementia-free' environment was attributed to the reach, adoption and adherence of the programme (Carone, Tischler, and Dening 2014).

It is important to note that recovery from mental illness refers to not only a reduction in symptoms, but achieving functional recovery through improvement in psychosocial functioning (Anthony 1993). Given that recovery is not a linear process, and community support has been identified as a fundamental component of recovery (Anthony 1993), the delivery of such programmes via professional footballs clubs are a promising intervention to help achieve improvements in psychosocial functioning and hence, recovery.

\section{The delivery of community mental health services within the confines of the football club}

One such programme that was delivered within the grounds of professional football clubs was the 'It's a Goal' programme (Pringle and Sayers 2004). The intervention typically targeted men aged 18-35 years and aimed to improve mental well-being. Using groupbased interventions, and utilising football as a metaphor, helped young adult men with mental illness to improve self-esteem, aid inclusion, and address the subject of suicide. This intervention did not include a physical activity element, however, professional football clubs were regarded as an innovative approach to making services accessible and promoting the uptake of mental health facilities with participants.

\section{Practical implications}


Despite limited published research on the outcomes of football-led mental health interventions, professional football clubs' FitC organisations are a growing delivery agent for mental health oriented programmes. There appears to be four major challenges however which warrant consideration in order to maximise successful implementation. These include facilitating partnerships with service providers, providing relevant continuing professional development of community coaches, adopting monitoring and evaluation frameworks, and the commissioning of interventions. Each potential challenge will briefly be considered.

\section{Facilitating partnerships with service providers}

A number of mental health interventions have been commenced without appropriate partnerships or strategies in place. As such, an open-door or walk-in approach to intervention design has resulted in uncertain group numbers, as well as a mix of participant conditions and therefore, needs. Where programmes have excelled, it has been a result of strategic and coherent partnership working. For example, Everton in the Community's Imagine Your Goals programme worked in partnership with Mersey Care NHS Trust. Working in partnership with Everton in the Community football coaches, Mersey Care ensure all participants' conditions and needs are met. This ensures that the participants most 'in need' are provided with consistent and quality care. Facilitating bilateral referral between mental health services and football-led interventions may also help to increase uptake and attendance, while ensuring adequate risk management strategies are followed whereby football programmes can deal with adverse events or escalation in symptoms appropriately. Recruitment strategies such as this should be viewed as best practice, in order to protect all stakeholders, and to ensure a consistent quality service for all participants.

\section{Continued professional development}

There is an acknowledgement of the lack of physical activity and health based qualifications by commentators and stakeholders concerned with the practice and engagement of professional football clubs on social agendas. Previous evidence has highlighted a lack of professional development opportunities for community football 
coaches working on the health agenda (Lansley and Parnell 2015). Whilst effective partnership working allows for informal, and formal, education exchanges between mental health organisations and community coaches there remains a need for an industry qualification. Football in the Community coaches, in this instance, should be skilled in mental health first aid and be aware of pathways by which adverse outcomes and/or increased symptoms can be reported and followed-up. Given the scope and growth of this it would appear relevant to look towards sport national governing bodies, government departments for health, and related agencies involved in sport, health, and physical activity (i.e., in the United Kingdom, SportsCoachUK), to address this issue. This is not a concern isolated to mental health promotion; indeed, evidence suggests that community coaches and practitioners working towards a health agenda require professional development (Curran et al. 2014, Bingham et al. 2014, Parnell et al. 2015) This remains an ongoing concern for those seeking high quality and effective delivery of interventions.

\section{Monitoring and evaluation}

Football-led interventions have the capacity to improve both physical and mental health outcomes of people experiencing mental illness (Parnell and Curran 2015). With growing interest in the utility of football-led interventions ensuring appropriate evaluation frameworks are in place is fundamental to demonstrating efficacy and justifying funding (Pringle et al. 2015). Researchers should consider non-traditional outcomes that may change in response to football-led interventions including (i) reduced stigma associated with mental health services, and any subsequent increase in traditional service utilisation, especially among young people, (ii) cardiorespiratory fitness which is known to be reduced among people experiencing mental illness and a key modifiable risk factor in response to physical activity (Stubbs et al. 2016, Vancampfort, Rosenbaum, Ward, et al. 2015, Vancampfort, Rosenbaum, Probst, et al. 2015), (iii) social connectedness, and (iv) self-confidence, quality of life and motivation (Vancampfort, Stubbs, Venigalla, et al. 2015, Vancampfort, Madou, et al. 2015). Ensuring that evaluation of interventions also extends to those involved in the design and delivery (i.e. coaches) must also be a fundamental consideration (Pringle et al. 2015). 


\section{Commissioning of interventions}

It appears that, in general, football-led mental health programmes have been commissioned like other, more typical, sport development programmes. Recent evidence (Lansley and Parnell 2015) provide an example from a football-led mental service. The authors detail the process whereby:

"funding has been provided to [a professional] football club community foundation to deliver a new area of work in football health improvement. This involved the community foundation delivering a 10-month football programme for participants with mental health issues on a budget of $£ 10,000$ without consideration of process or impact evaluation. This was not only a new area of work for the community foundation [i.e. working with participants with mental health issues], but also an agenda the current staff had little or no experience or any requisite skill for delivering."

It is important for healthcare to be equitable and effective. Commissioners may drive towards inflating programme targets in attempt to increase value for money. Therefore, as football and football settings are utilised as a vehicle for improving mental health outcomes, it is clear that policy makers, commissioners and managers need to be realistic about the associated costs and practical implications of delivering effective and equitable services (Lansley and Parnell 2015). Given that projects are often under-resourced and under-supported, this is something that is both urgent and important for all stakeholders to consider.

Commissioning could be the single most important factor in stimulating change in the area of mental health football-led interventions. This process could enact a situation whereby recipients of funding must evidence partnership working, continuing professional development planning for community coaches and evidence a clear monitoring and evaluation framework. For this to occur, it appears that commissioners must also consider their role within the process, reflect, and in some cases engage in their own professional development to enhance the effectiveness of their practice.

\section{Conclusion}

Moving forward, can professional football clubs' FitC organisations play an integral role in promoting mental health and increasing physical activity amongst people at- 
risk of developing, and people diagnosed with, mental illness? Indeed, the evidence suggests that professional football clubs can offer a potentially valuable ground for the delivery of applied PA interventions targeting mental health promotion or specifically tackling mental illness. Professional football clubs may also help facilitate access to mental health services, particularly among young people for whom accessing such services may be highly stigmatised. However, to capitalise on this opportunity funding agencies bodies and commissioners must provide appropriate resources (human and financial) for effective delivery and evaluation. Furthermore, a more strategic approach to working towards the mental health agenda must be adopted. This change in practice will offer professional football clubs a genuine opportunity to offer those in need access to high quality interventions. While professional football clubs may not be the panacea regarding improving mental health outcomes for all, the acceptability and scalability of football-based interventions warrants further investigation and investment from researchers and clinicians across the globe.

\section{Acknowledgements}

The authors would like to thank the peer reviewers of this article for the structured and critical feedback on the revisions and their continued support.

\section{References}

Alvarez-Jimenez, M., C. Gonzalez-Blanch, B. Crespo-Facorro, S. Hetrick, J. M. Rodriguez-Sanchez, R. Perez-Iglesias, and J. L. Vazquez-Barquero. 2008. "Antipsychotic-induced weight gain in chronic and first-episode psychotic disorders: a systematic critical reappraisal." CNS Drugs no. 22 (7):547-62.

Bangsbo, Jens, A. Junge, Jirí Dvorák, and Peter Krustrup. 2014. "Executive summary: Football for health-prevention and treatment of non-communicable diseases across the lifespan through football." Scandinavian journal of medicine \& science in sports no. 24 (S1):147-150.

Barclays Premier League. 2016. Imagine Your Goals 20162016].

Bingham, Daniel David, Daniel Parnell, Kathryn Curran, Roger Jones, and Dave Richardson. 2014. "Fit fans: Perspectives of a practitioner and understanding participant health needs within a health promotion programme for older men delivered within an English Premier League Football Club." Soccer \& Society no. 15 (6):883-901.

Britton, John. 2015. "Treating smoking in mental health settings." The Lancet Psychiatry no. 2 (5): 364-365. 
Carless, David, and Kitrina Douglas. 2008. "The role of sport and exercise in recovery from serious mental illness: two case studies." International Journal of Men's Health no. 7 (2).

Carone, Laura, Victoria Tischler, and Tom Dening. 2014. "Football and dementia: A qualitative investigation of a community based sports group for men with early onset dementia." Dementia:1471301214560239.

Cooke, Georga, Lisa Valenti, Paul Glasziou, and Helena Britt. 2012. "Common general practice presentations and publication frequency." Australian Family Physician no. 42 (1-2):65-68.

Curran, Kathryn, Daniel David Bingham, David Richardson, and Daniel Parnell. 2014. "Ethnographic engagement from within a Football in the Community programme at an English Premier League football club." Soccer \& Society no. 15 (6):934-950.

Curran, Kathryn, Barry Drust, and Dave Richardson. 2014. "'I just want to watch the match': a practitioner's reflective account of men's health themed match day events at an English Premier League football club." Soccer \& Society no. 15 (6):919-933.

Dipasquale, Salvatore, Carmine M. Pariante, Paola Dazzan, Eugenio Aguglia, Philip McGuire, and Valeria Mondelli. 2013. "The dietary pattern of patients with schizophrenia: a systematic review." Journal of psychiatric research no. 47 (2):197-207.

Elbe, A-M, S Barene, A Holtermann, and P Krustrup. 2015 [In press]. "Experiencing flow in a workplace physical activity intervention for female health care workers: A longitudinal comparison between football and Zumba." Women in Sport and Physical Activity Journal.

Firth, J., J. Cotter, R. Elliott, P. French, and A. R. Yung. 2015. "A systematic review and meta-analysis of exercise interventions in schizophrenia patients." Psychological Medicine no. 45 (7):1343-1361.

Gardner-Sood, P., J. Lally, S. Smith, Z. Atakan, K. Ismail, K. E. Greenwood, A. Keen, C. O'Brien, O. Onagbesan, C. Fung, E. Papanastasiou, J. Eberherd, A. Patel, R. Ohlsen, D. Stahl, A. David, D. Hopkins, R. M. Murray, and F. Gaughran. 2015. "Cardiovascular risk factors and metabolic syndrome in people with established psychotic illnesses: baseline data from the IMPaCT randomized controlled trial." Psychological Medicine no. 45 (12):2619-29. doi: doi:10.1017/S0033291715000562.

Henderson, Claire, Stefanie O'Hara, Graham Thornicroft, and Martin Webber. 2014. "Corporate social responsibility and mental health: The Premier League football Imagine Your Goals programme." International review of psychiatry no. 26 (4):460-466.

Holley, Jessica, Diane Crone, Philip Tyson, and Geoff Lovell. 2011. "The effects of physical activity on psychological well-being for those with schizophrenia: A systematic review." British journal of clinical psychology no. 50 (1):84-105.

Hulton, Andrew Thomas, David Flower, Rebecca Murphy, Dave Richardson, Barry Drust, and Kathryn Curran. 2015. "Effectiveness of a community football programme on improving physiological markers of health in a hard-to-reach male population: the role of exercise intensity." Soccer \& Society:1-13. 
Hunt, Kate, Sally Wyke, Cindy M. Gray, Annie S. Anderson, Adrian Brady, Christopher Bunn, Peter T. Donnan, Elisabeth Fenwick, Eleanor Grieve, and Jim Leishman. 2014. "A gender-sensitised weight loss and healthy living programme for overweight and obese men delivered by Scottish Premier League football clubs (FFIT): a pragmatic randomised controlled trial." The Lancet no. 383 (9924):1211-1221.

Hunter Institute of Mental Health. 2015. Prevention First: A Prevention and Promotion Framework for Mental Health. Newcastle: Hunter Institute of Mental Health.

Jayakody, K., S. Gunadasa, and C. Hosker. 2013. "Exercise for anxiety disorders: systematic review." Br J Sports Med no. 48 (3):187-196.

Krustrup, P., P. Aagaard, L. Nybo, J. Petersen, M. Mohr, and J. Bangsbo. 2010. "Recreational football as a health promoting activity: a topical review." Scandinavian journal of medicine \& science in sports no. 20 (s1):1-13.

Krustrup, Peter, Morten B. Randers, Lars J. Andersen, Sarah R. Jackman, Jens Bangsbo, and Peter R. Hansen. 2013. "Soccer improves fitness and attenuates cardiovascular risk factors in hypertensive men." Med Sci Sports Exerc no. 45 (3):553-560.

Lansley, Simon, and Daniel Parnell. 2015. "Football for health: getting strategic." Soccer \& Society:1-8.

Laursen, TM., T. Munk-Olsen, and M. Vestergaard. 2012. "Life expectancy and cardiovascular mortality in persons with schizophrenia." Curr Opin Psychiatry no. Mar 25 (2):83-8.

Lawrence, David, Kirsten J Hancock, and Stephen Kisely. 2013. "The gap in life expectancy from preventable physical illness in psychiatric patients in Western Australia: retrospective analysis of population based registers." British Medical Journal no. 346.

Mammen, George, and Guy Faulkner. 2013. "Physical activity and the prevention of depression: a systematic review of prospective studies." American Journal of Preventive Medicine no. 45 (5):649-657.

Medicine, Society of Behavioral Meidicine \& American College of Sports. 2015. Increase United States Health Plan Coverage for Exercise Programming in Community Mental Health Programs for People with Serious Mental Illness.

Notts Country Football in the Community. 2016. Working Age Dementia 20132016].

Nyboe, L., and H. Lund. 2013. "Low levels of physical activity in patients with severe mental illness." Nordic Journal of Psychiatry no. 67:43-46.

Ottesen, Laila, Rikke Schou Jeppesen, and Birgitte R. Krustrup. 2010. "The development of social capital through football and running: studying an intervention program for inactive women." Scandinavian journal of medicine \& science in sports no. 20 (s1):118-131.

Parnell, D., and K. Curran. 2015. "Professional football clubs could deliver pragmatic physical activity interventions to promote mental health." British journal of sports medicine:bjsports-2015-094582.

Parnell, D., and D. Richardson. 2014. "Special Issue: Football and inclusivity." Soccer and Society no. 15 (6):823-987.

Parnell, Daniel, and Andy Pringle. 2016. "Football and health improvement: an emerging field." Soccer \& Society no. 17 (2):171-174. 
Parnell, Daniel, Andy Pringle, Jim McKenna, Stephen Zwolinsky, Zoe Rutherford, Jackie Hargreaves, Lizzie Trotter, Michael Rigby, and David Richardson. 2015.

"Reaching older people with PA delivered in football clubs: the reach, adoption and implementation characteristics of the Extra Time Programme." BMC public health no. 15 (1):220.

Perez-Iglesias, Rocio, Benedicto Crespo-Facorro, Obdulia Martinez-Garcia, Maria L Ramirez-Bonilla, Mario Alvarez-Jimenez, Jose M Pelayo-Teran, Maria T GarciaUnzueta, Jose A Amado, and Jose L Vazquez-Barquero. 2008. "Weight gain induced by haloperidol, risperidone and olanzapine after 1 year: findings of a randomized clinical trial in a drug-naive population." Schizophrenia Research no. 99 (1):13-22.

Pringle, A., and P. Sayers. 2004. "It's a goal!: Basing a community psychiatric nursing service in a local football stadium." The Journal of the royal society for the promotion of health no. 124 (5):234-238.

Pringle, A. 2009. The growing role of football as a vehicle for interventions in mental health care. Journal of Psychiatric and Mental Health Nursing, 16: 553-557.

Pringle, Andy, Daniel Parnell, Zoe Rutherford, Jim McKenna, Stephen Zwolinsky, and Jackie Hargreaves. 2015. "Sustaining health improvement activities delivered in English professional football clubs using evaluation: a short communication." Soccer \& Society:1-11.

Pringle, Andy, Daniel Parnell, Stephen Zwolinsky, Jackie Hargreaves, and Jim McKenna. 2014. "Effect of a health-improvement pilot programme for older adults delivered by a professional football club: the Burton Albion case study." Soccer \& Society no. 15 (6):902-918.

Pringle, Andy, Stephen Zwolinsky, James McKenna, Steven Robertson, Andy DalySmith, and Alan White. 2014. "Health improvement for men and hard-to-engagemen delivered in English Premier League football clubs." Health education research no. 29 (3):503-520.

Rebar, Amanda L., Robert Stanton, David Geard, Camille Short, Mitch J. Duncan, and Corneel Vandelanotte. 2015. "A Meta-Meta-Analysis of the effect of physical activity on depression and anxiety in non-clinical adult populations." Health psychology review no. 9 (3):1-78.

Rosenbaum, S., A. Tiedemann, C. Sherrington, J. Curtis, and P. B. Ward. 2014. "Physical activity interventions for people with mental illness: a systematic review and meta-analysis." Journal of Clinical Psychiatry no. 75 (9):964-974.

Rosenbaum, S., A. Tiedemann, Philip B. Ward, Jackie Curtis, and Catherine Sherrington. 2015. "Physical activity interventions: an essential component in recovery from mental illness." British Journal of Sports Medicine no. 49. doi: 10.1136/bjsports2014-094314.

Rutherford, Zoe, Brendan Gough, Sarah Seymour-Smith, Christopher R. Matthews, John Wilcox, Dan Parnell, and Andy Pringle. 2014. "'Motivate': the effect of a Football in the Community delivered weight loss programme on over 35-year old men and women's cardiovascular risk factors." Soccer \& Society no. 15 (6):951969.

Schuch, Felipe Barreto, Andrea Camaz Deslandes, Brendon Stubbs, Natan Pereira Gosmann, Cristiano Tschiedel Belem da Silva, and Marcelo Pio de Almeida 
Fleck. 2016. "Neurobiological effects of exercise on major depressive disorder: A systematic review." Neuroscience \& Biobehavioral Reviews no. 61:1-11.

Snethen, Gretchen A., Bryan P. McCormick, and Paul H. Lysaker. 2014. "Physical Activity and Psychiatric Symptoms in Adults With Schizophrenia Spectrum Disorders." The Journal of Nervous and Mental Disease no. 202 (12):00-00.

Stanton, Robert, and Peter Reaburn. 2014. "Exercise and the treatment of depression: a review of the exercise program variables." Journal of Science and Medicine in Sport no. 17 (2):177-182.

Stanton, Robert, Simon Rosenbaum, Megan Kalucy, Peter Reaburn, and Brenda Happell. 2015. "A call to action: exercise as treatment for patients with mental illness." Australian journal of primary health no. 21 (2):120-125.

Stanton, Robert, Simon Rosenbaum, Peter Reaburn, and Brenda Happell. 2014. "A multidisciplinary approach to aerobic exercise prescription for mental illness." Sport Health no. 32 (3):58.

Stubbs, Brendon, Simon Rosenbaum, Davy Vancampfort, Philip B. Ward, and Felipe B. Schuch. 2016. "Exercise improves cardiorespiratory fitness in people with depression: A meta-analysis of randomized control trials." Journal of Affective Disorders no. 190:249-253.

Thompson, Paul D, David Buchner, Ileana L Piña, Gary J Balady, Mark A Williams, Bess H Marcus, Kathy Berra, Steven N Blair, Fernando Costa, and Barry Franklin. 2003. "Exercise and Physical Activity in the Prevention and Treatment of Atherosclerotic Cardiovascular Disease A Statement From the Council on Clinical Cardiology (Subcommittee on Exercise, Rehabilitation, and Prevention) and the Council on Nutrition, Physical Activity, and Metabolism (Subcommittee on Physical Activity)." Circulation no. 107 (24):3109-3116.

Thornicroft, G. 2011. "Physical health disparities and mental illness: the scandal of premature mortality." British Journal of Psychiatry no. 199 (6):441-2.

Vancampfort, D, S Rosenbaum, P. B Ward, and B Stubbs. 2015. "Exercise improves cardiorespiratory fitness in people with schizophrenia: a systematic review and meta-analysis." Schizophr Res.

Vancampfort, D, B Stubbs, PB Ward, SB Teasdale, and S Rosenbaum. 2015a. "Integrating physical activity as medicine in the care of people with severe mental illness." Australian and New Zealand Journal of Psychiatry no. 49 (8):681-682. doi: 10.1177/0004867415590831.

Vancampfort, D., M. De Hert, LH. Skjerven, AL. Gyllensten, A. Parker, N. Mulders, L. Nyboe, F. Spencer, and M. Probst. 2012. "International Organization of Physical Therapy in Mental Health consensus on physical activity within multidisciplinary rehabilitation programmes for minimising cardio-metabolic risk in patients with schizophrenia." Disability and rehabilitation no. 34 (1):1-12.

Vancampfort, D., S. Rosenbaum, M. Probst, A. Soundy, A. J. Mitchell, M. De Hert, and B. Stubbs. 2015. "Promotion of cardiorespiratory fitness in schizophrenia: a clinical overview and meta-analysis." Acta Psychiatrica Scandinavica.

Vancampfort, D., B. Stubbs, A. J. Mitchell, M De Hert, M Wampers, P. B Ward, S Rosenbaum, and C. U. Correll. 2015. "Risk of Metabolic Syndrome and its Components in People with Schizophrenia, Bipolar and Major Depressive 
Disorders: a Large Scale Meta-analysis of 198 Studies." World Psychiatry no. In press.

Vancampfort, Davy, and Guy Faulkner. 2014. "Physical activity and serious mental illness: A multidisciplinary call to action." Mental Health and Physical Activity no. 3 (7):153-154.

Vancampfort, Davy, Jan Knapen, Michel Probst, T Scheewe, Sander Remans, and Marc De Hert. 2012. "A systematic review of correlates of physical activity in patients with schizophrenia." Acta Psychiatrica Scandinavica no. 125 (5):352-362.

Vancampfort, Davy, Tomas Madou, Herman Moens, Tanja De Backer, Patrick Vanhalst, Chris Helon, Pieter Naert, Simon Rosenbaum, Brendon Stubbs, and Michel Probst. 2015. "Could autonomous motivation hold the key to successfully implementing lifestyle changes in affective disorders? A multicentre cross sectional study." Psychiatry research no. 228 (1):100-106.

Vancampfort, Davy, Michel Probst, Jan Knapen, Attilio Carraro, and Marc De Hert. 2012. "Associations between sedentary behaviour and metabolic parameters in patients with schizophrenia." Psychiatry Research no. 200 (2):73-78.

Vancampfort, Davy, Michel Probst, Liv Helvik Skjaerven, Daniel Catalán-Matamoros, Amanda Lundvik-Gyllensten, Antonia Gómez-Conesa, Rutger Ijntema, and Marc De Hert. 2012. "Systematic review of the benefits of physical therapy within a multidisciplinary care approach for people with schizophrenia." Physical Therapy no. 92 (1):11-23.

Vancampfort, Davy, Brendon Stubbs, Sumanth Kumar Venigalla, and Michel Probst. 2015. "Adopting and maintaining physical activity behaviours in people with severe mental illness: The importance of autonomous motivation." Preventive Medicine.

Vancampfort, Davy, Brendon Stubbs, Philip B. Ward, Scott Teasdale, and Simon Rosenbaum. 2015b. "Why moving more should be promoted for severe mental illness." The Lancet Psychiatry no. 2 (4):295. doi: 10.1016/S22150366(15)00099-1.

White, A, S Zwolinsky, A Pringle, J McKenna, A Daly-Smith, S Robertson, and R Berry. 2012. Premier League Health: A national programme of men's health promotion delivered in/by professional football clubs, Final Report 2012. Centre for Men's Health \& Centre for Active Lifestyles, Leeds Metropolitan University. 